\title{
Endometrial Aspiration Using MVA Syringe in Dysfunctional Uterine Bleeding
}

\author{
Abha Singh ${ }^{1}$, Suhagini Murmu2 ${ }^{2}$ \\ 1Professor \& Head, ${ }^{2}$ Post Graduate student, \\ Department of Obst \& Gyn, Pt. J. N. M. Medical College, Raipur, Chhattisgarh, India.
}

\begin{abstract}
Background: Dysfunctional uterine bleeding is a diagnosis of exclusion. Histopathological examination of endometrial aspiration is an important diagnostic tool in evaluating of DUB and a specific diagnosis could help the one to plan medical treatment and avoid unnecessary surgical intervention. This study was aimed to evaluate the endometrial Pattern in women of reproductive age presenting with DUB.

Methods: Endometrial aspiration was done in the outpatient department without anaesthesia, on 110 women presenting with symptoms of dysfunctional uterine bleeding.

Results: Histopathological examination of endometrial tissue showed a wide variety of endometrium ranging from normal endometrium to malignancy. Proliferative endometrium $(42.72 \%)$ is the most common endometrial pattern seen in the reproductive age group followed by secretory endometrium $(29.10 \%)$. The leading pathological finding in this study was endometrial hyperplasia in $26 \%$. Endometrial carcinoma was present in $1.8 \%$ whereas tubercular endometritis was detected in $0.91 \%$ only.
\end{abstract}

Conclusion: $71.82 \%$ of women were found to have

\section{INTRODUCTION}

Endometrium is a dynamic, hormonally sensitive and responsible tissue which constantly and rhythmically undergoes changes in the active reproductive life.

Abnormal uterine bleeding occurs in 9 to 14 percent of women in reproductive age, significantly impacting quality of life. Dysfunctional uterine bleeding is a clinical term used to describe bleeding not attributable to underlying organic pathologic condition. It is one of the leading causes of female morbidity in our country as it adds to the causes of anaemia which is already prevailing in women of our setup.

\section{METHODS}

All the women of reproductive age group attending the outpatient department and fulfilling the criteria of DUB were included in this study. Detailed history was taken regarding age, amount, duration \& pattern of bleeding \& other associated gynaecological problems. Ultrasonography was done to rule out any other pelvic pathology. Endometrial sampling was done using MVA syringe without anaesthesia and sent for histopathological examination. physiological endometrium. Thus, specific hormonal therapy was given to them. Endometrial aspiration by MVA syringe is a safe and effective office procedure and can be done in low resources setting.

Key Words: Dysfunctional uterine bleeding, Endometrium, Endometrial hyperplasia, Endometrial aspiration.

\section{*Correspondence to:}

Dr. Suhagini Murmu

Mohalla - Gitil Kocha, Kokar

P.O - Bariatu, DIST. Ranchi

Jharkhand, India.

Article History:

Received: 19-09-2016, Revised: 13-10-2016, Accepted: 21-10-2016

\begin{tabular}{|l|c|}
\hline \multicolumn{2}{|c|}{ Access this article online } \\
\hline $\begin{array}{l}\text { Website: } \\
\text { www.ijmrp.com }\end{array}$ & Quick Response code \\
\hline DOI: & \\
10.21276/ijmrp.2016.2.6.017 & \\
\hline
\end{tabular}

\section{RESULTS}

A total of 110 endometrial aspirations of women in reproductive age group were studied from a period of 12 months. Out of 110 , $60 \%$ women were in the age group of more than 40years. Whereas the incidence was high in parity two (37.27\%) and parity three $(29.09 \%)$. The different symptoms with which they presented are shown in Table 1.

Table 2 shows the different histopathological endometrial pattern. The histologic patterns of endometrium were correlated with age, and bleeding pattern. Correlation of endometrial pattern with age revealed that in all age group physiological pattern of endometrium is the most common finding whereas pathological condition was more common with advanced age.

Menorrhagia, metrorrhagia and amenorrhoea followed by bleeding were the common clinical presentation in the proliferative group, whereas polymenorrhoea was common in Secretory group. Menorrhagia was the most common clinical presentation in the pathological group as shown in Table 3. Correlation of clinical presentation with age group is shown in Table 4. 
Endometrial hyperplasia was the most common pathological finding in the present study and was of cystic type in $73 \%$ as shown in Table 5.
Malignancy is a major differential diagnosis in women with DUB in perimenopausal age group. In our study frequency of endometrial carcinoma was $1.8 \%$ only.

Table1: Distribution of women according to clinical presentation.

\begin{tabular}{lcc}
\hline Presentation of women & No. Of women & Percentage \\
\hline Menorrhagia & 69 & $62.03 \%$ \\
Metrorrhagia & 12 & $10.9 \%$ \\
Amenorrhoea followed by bleeding & 9 & $8.1 \%$ \\
Menometrorrhagia & 6 & $5.4 \%$ \\
Oligomenorrhoea & 3 & $2.7 \%$ \\
Total & 110 & $100 \%$ \\
\hline
\end{tabular}

Table 2: Distribution of women according to endometrial pattern

\begin{tabular}{lcc}
\hline Endometrial pattern & Total no of women & Percentage \\
\hline Proliferative phase & 47 & $42.72 \%$ \\
Secretory phase & 32 & $29.10 \%$ \\
Hyperplasia & 28 & $25.45 \%$ \\
Endometrial ca & 02 & $1.82 \%$ \\
Tubercular endometritis & 01 & $0.91 \%$ \\
Total & 110 & $100 \%$ \\
\hline
\end{tabular}

Table 3: Relation between clinical presentation and types of endometrium

\begin{tabular}{lccccc}
\hline Endometrial pattern & Menorrhagia & Metrorrhagia & Polymenorrhea & $\begin{array}{c}\text { Meno- } \\
\text { Metrorrhagia }\end{array}$ & $\begin{array}{c}\text { Amenorrhea followed } \\
\text { by bleeding }\end{array}$ \\
\hline Proliferative phase & 32 & 8 & 5 & 4 & 6 \\
Secretory phase & 13 & 1 & 6 & 1 & 1 \\
Hyperplasia & 21 & 3 & - & 1 & 2 \\
Tuberculosis & 1 & - & - & - & - \\
Endometrial carcinoma & 2 & - & - & - & - \\
Total & $\mathbf{6 6}$ & $\mathbf{1 2}$ & $\mathbf{5}$ & $\mathbf{9}$ \\
\hline
\end{tabular}

Table 4: Bleeding pattern in relation to age group

\begin{tabular}{|c|c|c|c|c|}
\hline Type of bleeding & $21-30$ years. & $31-40$ years. & $>40$ years. & Total \\
\hline Menorrhagia & 02 & 25 & 42 & 69 \\
\hline Polymenorrhoea & & 06 & 05 & 11 \\
\hline Oligomenorrhoea & 02 & 01 & - & 03 \\
\hline Metrorrhagia & - & 02 & 10 & 12 \\
\hline Menometrorrhagia & - & 01 & 05 & 06 \\
\hline Amenorrhoea followed by bleeding & - & 01 & 08 & 09 \\
\hline
\end{tabular}

Table 5: Distribution of women according to endometrial hyperplasia

\begin{tabular}{lcc}
\hline Endometrial hyperplasia & Total no of women & Percentage \\
\hline Simple cystic hyperplasia & 22 & $78 \%$ \\
Complex hyperplasia without atypia & 04 & $14 \%$ \\
Atypical hyperplasia & 02 & $08 \%$ \\
Total & 28 & $100 \%$ \\
\hline
\end{tabular}

\section{DISCUSSION}

Incidence of dysfunctional uterine bleeding was found to be $9.1 \%$ of women in reproductive age group who visited the OPD in our hospital. The commonest age group presenting with excessive bleeding in our study was more than 40 years but it was also observed that no age was exempted from this disease.

There is variance with reports of other researchers where DUB was more commonly encountered in their fourth decades of life. We found a greater percentage as compared to Doraswami et al ${ }^{1}$,
Dadhania et $\mathrm{al}^{2}$ and $\mathrm{R}$ Shah et $\mathrm{al}^{3}$. A higher incidence than our study was reported by R Damle et al ${ }^{4}$ and Shazia Anjum et al ${ }^{5}$. Majority of women included in our study, presented clinically with menorrhagia $(62.03 \%)$. It was the most common clinical presentation seen in other studies also.4-8

DUB has great variation in the endometrial patterns and its management entirely depends upon the type of endometrial pattern. Our study like several others showed that proliferative, 
secretory and endometrial hyperplasia occurs more commonly in the age above 40 years. Predominant number of women in this study showed normal physiologic phases such as proliferative $(51.8 \%)$ and secretory endometrium $(29.09 \%)$, similar to Doraswami et $\mathrm{al}^{1}$, Arti Anvikar et $\mathrm{l}^{8}$, Usha Doddamani et $\mathrm{al}^{9}$, Deshmukh et $\mathrm{al}^{10}$, Parmar et al11 and A Khare et al ${ }^{12}$. Many of the women in this group were managed by reassurance and pharmacological treatment.

Endometrial hyperplasia (25\%) is the leading pathological finding in this study and is of cystic type, this figure was similar to the study done by Damle et $\mathrm{al}^{4}$, Arti Anvikar et $\mathrm{al}^{8}$ and A Khare ${ }^{11}$. A higher incidence of $41.9 \%$ was reported by Smita et $a^{6}$. Identification of endometrial hyperplasia is important because they are thought to be precursors of endometrial carcinoma. An earlier stage of presentation due to increased health awareness could explain the high incidence in our study. Diagnosing the woman at the earlier stage will be of definitive help to the gynecologists to prevent the disease progression.

Tubercular endometritis was not a common condition as generally considered in India. There was a single case detected in the present study as also in other studies by Doraswami et al ${ }^{1}$ and Damle et $\mathrm{al}^{4}$.

In the present study, the frequency of endometrial carcinoma was low, which denotes the frequency of endometrial carcinoma is low in reproductive age group in our country. It is higher than the study done by RPatil et $\mathrm{al}^{7}(1.05 \%)$ and Arti Anvikar et al ${ }^{8}(1.2 \%)$ and lower than the study done by Doraswami et al ${ }^{1}(4.4 \%)$.

\section{CONCLUSION}

In this study, the most frequent finding seen in women with DUB in reproductive age group was physiological pattern of endometrium. In the modern era medical treatment is preferred over hysterectomy by knowing the exact cause of DUB and avoiding unwarranted hysterectomy. Only $6.3 \%$ of our women needed hysterectomy. Currently outpatient endometrial aspiration by MVA syringe is the first line diagnostic test in evaluating the endometrial pattern. The newer method of endometrial assessment is hysteroscopic guided biopsy. It requires its availability, skill of the surgeon and is must in assessment of postmenopausal women for ruling out endometrial carcinoma. Endometrial aspiration by MVA syringe is a safe and effective office procedure. It does not require any anaesthesia and special skill. It and can be done in low resources setting. It is convenient to the women and gynecologists and has the advantage of taking aspiration on the first visit of women, when they come with heavy menstrual flow and also waiting time for early diagnosis of malignancy can be reduced.

Globally $50 \%$ of hysterectomies are performed for DUB. The hysterectomy rate in India is 2.3 million per year. ${ }^{13}$ The hospital cost and financial burden on families can be brought down dramatically if DUB is properly diagnosed and managed medically after performing a simple procedure of endometrial assessment in all women with menstrual disorders.

\section{REFERENCES}

1. Saraswathi D, Thanka J, Shalinee R, Aarti R, jayaV, Kumar PV. Study of endometrial pathology in abnormal uterine bleeding. Obstet Gynaecol India.2011;61 (4):426-430.
2. Dadhania B, Dhruva G, Agravat A, Pujara K. Histopathological study of endometrium in dysfunctional uterine bleeding. Int J Res Med. 2013; 2(1); 20-24.

3. Shah R, Dayal A, Kothari S, Patel S, Dalal B. Histopathological interpretation of endometrium in abnormal uterine bleeding. Int $\mathrm{J}$ Med Sci Pub Health.2014; 3(4): 452-456.

4. Damle RP, Dravid NV, Suryavanshi KH, Gadre AS, Bagale PS, Ahire N. Clinocopathological spectrum of endometrial changes in perimenopausal and postmenopausal abnormal uterine bleeding: A 2 years study. Journal of clinical and diagnostic research. 2013;7(12):2774-2776.

5. Anjum S, Gawai S, Mudkhedkar R, Padam Bakai. Clinical presentation and histopathological evaluation of endometrium in perimenopausal uterine bleeding. International journal of recent trends in science and technology. 2014; 10(1):187-188.

6. Patne SS, Sirpurkar MS. Validation of endometrial curettage in abnormal uterine bleeding in a teaching institute of central India. Int J Med Res Health Sci. 2013;2(3):491-495.

7. Patil R, Patil RK, Andola SK, Laheru V, Bhandar M. Histopathological spectrum of endometrium in dysfunctional uterine bleeding. Int J Biol Med Res,2013;4(1):2798-2801.

8. Anvikar A, Ramteerthakar N, Sulhyan K. Abnormal uterine bleeding- A clinicopathological study of 160 cases. Asian J Med Sci. 2013;2(1):15-18.

9. Doddamani UG, Doddamani GB, Katageri G, Mallapur A. Clinicopathological correlation of endometrium in abnormal uterine bleeding. Sch J App Med Sci. 2014;2(1A): 46-49.

10. Deshmukh V, Yelikar KA, Davile M. Clinical study of endometrial pattern in Dysfunctional Uterine Bleeding by Transvaginal Sonography and its histopathological correlation. Journal of Evolution of Medical and Dental Sciences. 2013 (2):2440-2445.

11. Parmar J, Desai D. Study of endometrial pathology in abnormal uterine bleeding. Int J Reprod Contracept Obstet Gynaecol.2013 Jun;2(2):182-185.

12. Khare A, Bansal R, Sharma S, Elhence P, Makkar N, Tyagi Y. Morphological spectrum of endometrium in patients presenting with DUB. People's Journal of scientific Research. 2012; 2 (5): 1316.

13. Statistics by country for hysterectomy. Last update: Feb, 2012. http://www. Rightdiagnosis.com/h/hysterectomy/stats-country.htm.

\section{Source of Support: Nil. Conflict of Interest: None Declared.}

Copyright: (c) the author(s) and publisher. IJMRP is an official publication of Ibn Sina Academy of Medieval Medicine \& Sciences, registered in 2001 under Indian Trusts Act, 1882.

This is an open access article distributed under the terms of the Creative Commons Attribution Non-commercial License, which permits unrestricted non-commercial use, distribution, and reproduction in any medium, provided the original work is properly cited.

Cite this article as: Abha Singh, Suhagini Murmu. Endometrial Aspiration Using MVA Syringe in Dysfunctional Uterine Bleeding. Int J Med Res Prof. 2016; 2(6):92-94.

DOI: 10.21276/ijmrp.2016.2.6.017 